\title{
변화분석(Theory of Change)과 개발협력사업 성과관리 고찰
}

목 차

I. 개요

II. 성과관리와 성과분석모형(Results Framework)

III. 성과관리와 논리모형모델(Logframe)

1. 성과관리도구로서의 논리모형모델(Logframe)

2. 논리모형모델(Logframe)의 한계

IV. 변화분석(Theory of Change)과 성과관리

1. 변화분석(Theory of Change)의 다양한 정의

2. 변화분석(Theory of Change)의 사용법

1) 국별, 섹터별 정책 분석

2) 사업계획 수립

3) 평가

3. 변화분석(Theory of Change)과 논리모형모델(Logframe)

V. 결론

1. 체계적인 원조 데이터 관리 및 활용 방안 마련

2. 개발도상국의 데이터 관리 및 통계 역량 강화 지원

\section{I. 개요}

개발협력에서 성과관리의 중요성이 점차 증대되고 있다. 1990년대 이후 본격적으로 대두된 원조 피로현상은 원조에 대한 회의를 증대시켰고 이에 대한 대안으로 개발협력사업 성과관리를 강화하여 원조효과성을 높이겠다는 논의가 대두되었다. 이러한 논의는 2008년 글로벌 금융위기 이후 원조예 
산 증대가 점점 더 어려워지는 상황 속에서 점차 강화되었다. 따라서 개발협력관련 기관들은 성과관 리방안을 고민하게 되었고, 성과분석모형(Results Framework)에 기반한 다양한 성과관리도구들을 활용하기 시작하였다.

개별사업의 성과관리에 가장 널리 활용되는 도구는 1960년대 미국 USAID에서 고안된 Logical Framework이다. Logical Framework(이하 Logframe)는 사업기획단계에서부터 개발협력사업 이 의도한 소기의 개발성과를 모니터링과 평가를 위한 성과지표와 함께 기술하도록 작성된다. 이렇 게 성과와 측정지표가 함께 기술되기 때문에 Logframe은 성과관리를 위한 유용한 도구(Tool)가 된 다. 그러나 Logical Framework 자체에 한계가 없는 것은 아니다. 따라서 이에 대한 보완책으로서 2000년대부터 Theory of Change(변화분석 $)^{1}$ 에 기초한 성과관리기법이 주목을 받게 되었다.

현재 우리나라에서 개발협력성과관리에는 Logframe이 가장 널리 활용되고 있으나, Logframe이 갖는 성과분석모형으로서의 의미에 대한 논의는 활발하지 않으며, Theory of Change와 관련된 논 의 또한 본격적으로 대두되지 않고 있다. 따라서 본 연구에서는 성과관리와 Results Framework 그 리고 Logframe의 관계를 살펴보고, 아직까지 국내에서는 생소한 Theory of Change의 정의와 활 용법을 논의한 뒤 이러한 새로운 성과관리도구가 우리나라의 원조사업 추진에 주는 함의가 무엇인지 를 분석하고자 한다.

\section{II. 성과관리와 성과분석모형(Results Framework)}

국제개발협력에서 효과성(Effectiveness)은 점차 중요성을 갖게 되었다. 효과성이란 일반적으로 대상이 목표를 달성한 정도를 말한다. 따라서 국제개발협력에서 효과성은 일반적으로 정책, 전략 또 는 사업들이 계획한 목표를 얼마나 달성했는지를 측정하는 방식으로 진행된다. 개발협력에서 효과성 분석은 정책이나 전략, 사업들이 계획했던 산출물을 도출해냈는가를 확인하는 산출물 분석(output analysis)보다는 각각의 정책이나 전략, 사업이 계획했던 개발성과(results)를 얼마나 달성했는지를 확인하는 방식으로 추진된다.

이렇게 개발협력분야에서 사업의 산출물이 아닌 개발성과에 초점을 맞추는 이유는 실제 개발협력

1) Theory of Change는 변화이론으로 번역되는 경우가 많으나, 동 번역은 자칫 Theory of Change를 하나의 별도 학 설이나 이론체제로 오해하게 될 소지가 있어, 본 연구에서는 변화를 이끄는 요인이나 가정들에 대한 분석이라는 Theory of Change 원래의 의미와 특성을 반영하여 변화분석으로 의역했다. 본 연구에서는 이러한 번역의 오류를 줄이고자 변화분석은 그대로 Theory of Change(TOC)로 지칭한다. 
사업이 산출물을 도출하고도 성과달성에는 실패하는 경우가 많기 때문이다. 가령, 벽지농촌에 초등 학교를 건립하는 사업을 기획 및 추진한다고 가정하였을 때, 사업 종료 시 초등학교 건립이라는 산 출물을 $100 \%$ 계획대로 도출하는데 성공했다 하더라도, 이것이 초등학교 취학률이나, 졸업률, 문자 해독률 등의 개선이라는 개발성과로 제대로 이어지지 못하는 경우가 발생할 수 있는 것이다.

제I장

따라서, 개발협력기관들은 정책이나 전략, 사업들이 계획했던 개발성과를 달성할 수 있도록 하 기 위해서는 계획단계부터 실행, 종료단계에 이르기까지 전 단계를 관리해야 한다는 성과중심관리 (Results Management)를 강조하기 시작하였고, 동시에 성과분석모형(Results Framework)은 성 과중심관리의 주요 도구(Key Tool)로서 중요성을 갖게 되었다.

성과분석모형이란 개발전략 또는 개발사업(프로그램이나 프로젝트 모두 포함)과 같은 특정한 개 발행위들이 달성할 것으로 예측되는 서로 다른 준위의 연쇄적인 성과들에 대한 구체화된 표현(an explicit articulation)으로 정의할 수 있으며(World Bank, 2012), 본 모형의 표현방식은 그림, 표, 또는 서술 등 모두가 될 수 있다. 여기서 말하는 성과란 일반적으로 산출물(output), 개발목적 (outcome), 그리고 이들을 통해 달성할 장기목표(goal)를 포함한다. 의미는 유사하나 성과를 표현하 는 용어들과 구분은 각 기관별로 차이를 보인다. 예를 들어, 세계은행의 경우, 개발목적을 중간목표 (Intermediate Outcome)로, 장기목표는 목표(Outcome) 또는 영향(Impact)라고 지칭하기도 한다. 사용하는 용어상의 차이는 있으나, 성과분석모형에서 성과란 장기적인 개발목표 달성을 위한 일련의 세부목적, 목표들과 이들을 위해 실행된 개발행위들(development activities)의 산출물을 의미한다 는 점은 모두 동일하다.

이러한 성과들 간의 인과관계(Cause-effect Linkage)를 규명하는 작업이 성과분석모형 구성의 핵심요소이다. 실제로, 복잡하고 유동적인 개발협력 환경에서 일련의 논리적인 인과관계를 도출해내 기란 쉬운 일이 아니다. 하지만 잘 작성된 성과분석모형은 산출물-목적-장기목표 사이의 명확한 인 과관계를 보여준다. 이를 통해, 이해관계자들이 개발정책이나 사업계획의 당위성에 대한 보다 심도 있는 이해를 할 수 있게 되며, 이로써 정책과 사업의 효율성과 효과성이 증대될 수 있다.

성과분석모형이 논리적으로 작성되면 각 단계별로 달성기한과 함께 달성정도를 측정할 수 있는 지표를 개발하게 되고 이를 통해 성과분석모형은 모니터링과 평가에 활용된다.

일반적으로 개발협력기관들은 각 사업별로, 그리고 국별전략별로 성과분석모형을 작성, 활용한 다 (〈표 1,2$\rangle$ 참조). 대부분의 개발협력기관들은 각 수원국별 환경과 맥락, 특성, 수원국 정부의 전 략 등을 반영하여 국별지원전략을 수립하고 그에 따라 개별사업을 추진한다. 따라서 개발협력기관들 은 국별지원전략과 추진사업의 논리성을 검증하고 효과성을 제고하기 위하여 성과분석모형을 활용 한다.

\section{제II장}

제III장 
〈표 1〉 국별전략수준의 성과분석모형의 일반적인 예시

\begin{tabular}{|c|c|c|c|c|}
\hline 국가개발목표 & $\begin{array}{c}\text { 이슈/장애물/ } \\
\text { 핵심가정 }\end{array}$ & 예상 성과 & $\begin{array}{c}\text { 예상 산출물/ } \\
\text { 마일스톤 }\end{array}$ & 모니터링 활용 \\
\hline 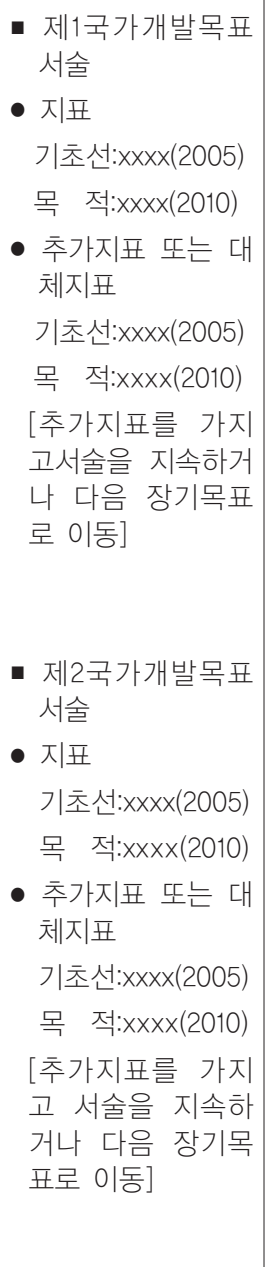 & $\begin{array}{l}\text { [국가개발목표 달 } \\
\text { 성에 대한 핵심 } \\
\text { 이슈 및 장애요 } \\
\text { 소 파악] }\end{array}$ & $\begin{array}{l}\text { - 제1성과 서술 } \\
\text { - 지표 } \\
\text { 기초선:xxxx(2005) } \\
\text { 중간선:xxxx(2007) } \\
\text { 목 적:xxxx(2010) } \\
\text { - 추가지표 또는 대 } \\
\text { 체지표 } \\
\text { 기초선:xxxx(2005) } \\
\text { 중간선:xxxx(2007) } \\
\text { 목 적:xxxx(2010) } \\
\text { [추가지표를 가지 } \\
\text { 고 서술을 지속하 } \\
\text { 거나 다음 성과로 } \\
\text { 이동] } \\
\text { 제2성과 서술 } \\
\text { - 지표 } \\
\text { 기초선:xxxx(2005) } \\
\text { 중간선:xxxx(2007) } \\
\text { 목 적:xxxx(2010) } \\
\text { - 추가지표 또는 대 } \\
\text { 체지표 } \\
\text { 기초선:xxxx(2005) } \\
\text { 중간선:xxxx(2007) } \\
\text { 목 적:xxxx(2010) } \\
\text { [추가지표를 가지 } \\
\text { 고 서술을 지속하 } \\
\text { 거나 다음 성과로 } \\
\text { 이동] }\end{array}$ & $\begin{array}{c}\text { - 성과분석모형 소 } \\
\text { 요시간 내에 파악 } \\
\text { 될 것으로 기대되 } \\
\text { 는 제 } 1 \text { 산출물/마일 } \\
\text { 스톤에 대한 서술 } \\
\text { - 지표(마일스톤이 } \\
\text { 정량적으로 달성 } \\
\text { 가능한 경우) } \\
\text { 기초선:xxxx(2005) } \\
\text { 목 적:xxxx(2006) } \\
\quad x \times x \times(2007) \\
\quad x \times x \times(2008) \\
\quad x \times x \times(2009) \\
\quad x \times x \times(2010) \\
\text { - 추가지표 또는 대 } \\
\text { 체지표 (마일스톤 } \\
\text { 이 정성적으로 달 } \\
\text { 성가능한 경우) } \\
\text { [추가지표를 가지 } \\
\text { 고 서술을 지속하 } \\
\text { 거나 다음 마일스 } \\
\text { 톤으로 이동] } \\
\text { - 제2산출물/마일스 } \\
\text { 톤에 대한 서술 } \\
\text { [위와 동일] }\end{array}$ & $\begin{array}{l}\text { [본 정보의 추후 } \\
\text { 활용방안에 대해 } \\
\text { 강조하여 서술한 } \\
\text { 짧은 설명 제공] }\end{array}$ \\
\hline
\end{tabular}

* 출처: World Bank (2012)

특히, 사업별 성과관리를 위해서는 아래의〈표 2〉의 성과분석모형과 정량지표를 보다 세분화 및 구체화함으로써 〈표 3〉과 같이 구체적인 표로 작성한다. 보다 객관적인 측정 및 분석을 위해서는 $\triangle$ 각각의 산출물, 개발목적, 목표에 대한 기초선조사의 결과데이터, $\triangle$ 각 성과에 대한 측정지표, $\triangle$ 사 업기간 동안 연도별로 달성해야하는 지표의 수준, $\triangle$ 지표출처가 될 모니터링 보고서의 작성 빈도와 방법, 작성책임자 등을 포함 - 정리해야한다. 이를 통해 사업별 목표달성 정도를 객관적으로 측정하 고 분석할 수 있도록 하는 것이 오늘날 개발협력 및 원조사업의 관리 추세이다. 
〈표 2〉사업수준의 성과분석모형의 일반적인 예시

\begin{tabular}{|c|c|c|}
\hline 프로젝트 개발목표 & 프로젝트 개발 목표 지수 & 성과모니터링 활용 \\
\hline $\begin{array}{l}\text {-소규모 생산자의 생산성 증대 } \\
\text { 프로젝트 시행 지역 내 목표 작 } \\
\text { 물에 대한 시장접근성 증대 }\end{array}$ & $\begin{array}{l}\text {-목표 가치사슬 내 작물의 평균 } \\
\text { 산출량(바나나, 쌀, 커피 및 유 } \\
\text { 제품) } \\
\text { (단위: 각각 톤/헥타르/소 한 } \\
\text { 마리당 리터값) }\end{array}$ & $\begin{array}{l}\text {-프로젝트 개발 목표 지수는 아 } \\
\text { 래 목적을 달성하기 위해 실시 } \\
\text { 하는 하위 프로젝트 또는 다른 } \\
\text { 프로젝트 투자의 효율성 및 효 } \\
\text { 과성 수준을 보여줌 } \\
\text { - 농작물 생산성 제고(산출량 } \\
\text { 증대) } \\
\text { - 목표 가치사슬의 시장 잉여 } \\
\text { (시장거래된 생산량 중 일 } \\
\text { 부) 발생 }\end{array}$ \\
\hline 중간 성과 & 성과 지표 & 성과 모니터링 활용 \\
\hline $\begin{array}{l}\text { - 구성요소1: 농경기술이전 및 시 } \\
\text { 장과의 연계 }\end{array}$ & $\begin{array}{l}\text {-생산과정, 수확 후 관리, 공정 } \\
\text { 등 전 단계에 해당하는 신기술 } \\
\text { 패키지를 사용하고 있는 농부 } \\
\text { (여성/남성)의 참가 비중 } \\
\text {-우유생산을 위해 축산업에 종 } \\
\text { 사중인 생산자 비중 } \\
\text { - 시장대리인과 계약을 체결한 } \\
\text { 생산자 그룹/협회/협동조합 } \\
\text { 비중 } \\
\text {-신기술패키지 및 시장연계 달 } \\
\text { 성을 통한 프로젝트 직접 수혜 } \\
\text { 자의 수 } \\
\text {-신기술패키지 및 시장연계 달 } \\
\text { 성을 통한 프로젝트 간접 수혜 } \\
\text { 자의 수 }\end{array}$ & $\begin{array}{l}\text { 본 지수는 아래와 같은 내용을 } \\
\text { 나타냄 } \\
\text {-농부들의 신기술 도입 지원에 } \\
\text { 대한 본 프로젝트의 효과성 } \\
\text { •지식전달 및 자문서비스의 효 } \\
\text { 과성 } \\
\text { - 생산자그룹/협회/협동조합의 } \\
\text { 상업용 작물 생산 정도 } \\
\text { •본 프로젝트가 해당 지역의 다 } \\
\text { 른 거주민들에게 미치는 영향 } \\
\text { •하위 프로젝트 종료에 대한전 } \\
\text { 반적인 효과성 }\end{array}$ \\
\hline
\end{tabular}

* 출처: World Bank (2012)

즉, 성과분석모형이란 개발협력정책이나 전략, 사업이 기획한 산출물과 목적을 달성하는지를 측 정하여 정책, 전략, 사업의 효과성을 높이기 위한 도구라고 할 수 있으며, 이 모형은 개발행위-산출 물-목적-장기목표 간의 원인과 결과관계를 명료하게 나타냄으로써 정책, 전략, 사업의 추진 당위성 과 기획의 합리성을 이해관계자들이 모두 공유할 수 있도록 한다. 현재 대부분의 개발협력관련 기관 들은 국별전략과 사업기획문서(Project Document)의 성과관리를 동 모형을 통해 수행하고 있으며, 특히 사업성과관리를 위해서는 모니터링과 평가방법을 결합시킨 사업성과분석모형을 사용한다. 
〈표 3〉사업별 성과관리의 정량지표 및 모니터링 보고서 작성 예시

\begin{tabular}{|c|c|c|c|c|c|c|c|}
\hline & \multirow[b]{2}{*}{ 프로젝트 성과 지표 } & \multirow[b]{2}{*}{ 기초선 } & \multicolumn{5}{|c|}{ 목표치 } \\
\hline & & & 1년차 & 2년차 & 3년차 & 4년차 & $\begin{array}{l}\text { 5년차 } \\
\text { (목표) }\end{array}$ \\
\hline \multicolumn{8}{|c|}{ 작물의 평균 산출량 } \\
\hline A & 쌀(톤/헥타르) & 2.5 & 2.8 & 3.3 & 3.8 & 4.0 & 4.0 \\
\hline B & 바나나(톤/헥타르) & 9.0 & NA & 12 & 14 & 16 & 16 \\
\hline $\mathrm{C}$ & 커피(체리 톤/헥타르) & 0.4 & 0.5 & 0.6 & 0.7 & 0.8 & 0.8 \\
\hline D & 우유(리터/연간) & 360 & 400 & 500 & 650 & 800 & 950 \\
\hline \multirow[t]{2}{*}{$E$} & $\begin{array}{l}\text { 참여생산자들에 의해 } \\
\text { 시장판매된 가치사슬 목표치 } \\
\text { 대비 작물의 생산량 비율 }\end{array}$ & 10 & 12 & 18 & 22 & 26 & 30 \\
\hline & & & \multicolumn{5}{|c|}{ 목표치 (누적값) } \\
\hline
\end{tabular}

\section{농작물 생산성 및 시장판매 프로세스}

\begin{tabular}{c|l|c|c|c|c|c|c}
\hline & $\begin{array}{l}\text { 생산과정, 수확 후 관리, 공정 } \\
\text { 등 전 단계에 해당하는 신기 } \\
\text { 술패키지를 사용하고 있는 농 } \\
\text { 부(여성/남성)의 참가 비중 }\end{array}$ & 10 & 15 & 30 & 45 & 60 & 70 \\
\hline$G$ & $\begin{array}{l}\text { 우유생산을 위해 축산업에 종 } \\
\text { 사중인 생산자 비중 }\end{array}$ & 10 & 15 & 30 & 45 & 60 & 70 \\
\hline & $\begin{array}{l}\text { 시장대리인과 계약을 체결한 } \\
\text { 생산자 그룹/협회/협동조합 } \\
\text { 비중 }\end{array}$ & 0 & 2 & 5 & 10 & 15 & 20 \\
\hline
\end{tabular}

정보수집 및 보고

정보수집 빈도 및 보고

정보수집 방법

정보수집 담당책임자

작물의 평균 산출량

\begin{tabular}{c|l|l|c}
\hline $\mathrm{A}$ & 수확기 말 & 생산자 설문조사 (연간) & PCU \\
\hline $\mathrm{B}$ & 연1회 판매기간 말 & 생산자 설문조사 (연간) & $\mathrm{PCU}$ \\
\hline $\mathrm{C}$ & 연1회 판매기간 말 & 생산자 설문조사 (연간) & $\mathrm{PCU}$ \\
\hline $\mathrm{D}$ & 연1회 판매기간 말 & 생산자 설문조사 (연간) & $\mathrm{PCU}$ \\
\hline $\mathrm{E}$ & 연1회 판매기간 말 & 생산자 설문조사 (연간) & $\mathrm{PCU}$ \\
\hline
\end{tabular}

\section{농작물 생산성 및 시장판매 프로세스}

\begin{tabular}{l|l|l|c}
\hline$F$ & 수확기/연1회 & 수확기/연1회 표본조사 & IPCU/PSP \\
\hline$G$ & 연1회 & 표본조사(연간) & IPCU/PSP \\
\hline$H$ & 연1회 & 표본조사(연간) & IPCU/PSP \\
\hline
\end{tabular}

* PCU: Project Coordination Unit

** IPCU: Inter-Provincial Coordinating Unit/PSP: Private Service Providers

출처: World Bank (2012) 


\section{III. 성과관리와 Logframe}

\section{1. 성과관리도구로서의 Logframe}

우리나라 개발협력관련 기관들 사이에서 가장 널리 알려진 성과분석모형은 Logframe ${ }^{2)}$ 이다. Logframe은 현재 가장 널리 쓰이는 개발협력사업 성과 관리 도구이기도 하다. 1960년대에 USAID 에서 고안된 logframe은 보기에는 단순해 보이는 4열과 4행의 표이다(〈표4〉참조).

제I장

제II장

제III장

〈표 4〉 Logframe의 구조와 내용

\begin{tabular}{|c|c|c|c|}
\hline Narrative Summary & $\begin{array}{l}\text { Objectively Veriable } \\
\text { Indicators(OVI) }\end{array}$ & $\begin{array}{c}\text { Means of } \\
\text { Verification(MOV) }\end{array}$ & Assumptions \\
\hline $\begin{array}{l}\text { Goal(목표) } \\
\text { 프로젝트가 기여하는 섹 } \\
\text { 터수준 또는 국가수준의 } \\
\text { 장기적 개발목표 } \\
\text { 작성방법: 장기에 걸쳐 } \\
\text { 이미 성취된 것처럼 과 } \\
\text { 거시제 동사로 시작 }\end{array}$ & $\begin{array}{l}\text { 상위수준 파급효과, 즉 } \\
\text { 목표수준을 측정하기 위 } \\
\text { 한 질문이나 지표 등의 } \\
\text { 방법 } \\
\text { (수량, 질, 시간 포함) }\end{array}$ & $\begin{array}{l}\text { 필요정보 수집방법: 데 } \\
\text { 이터 수집 주체, 빈도, } \\
\text { 정보 수입원(source)기입 }\end{array}$ & $\begin{array}{l}\text { 프로젝트의 장기적 지속 } \\
\text { 가능성을 위해 충족되어 } \\
\text { 야할 가정 }\end{array}$ \\
\hline $\begin{array}{l}\text { Purpose(목적) } \\
\text { 프로젝트의 직접적 목 } \\
\text { 적, 프로젝트의 직접적 } \\
\text { 결과에 의한 (수혜자그 } \\
\text { 룹의) 행동, 태도, 자원 } \\
\text { 등의 측면의 통합적이며 } \\
\text { 측정가능한 변화 } \\
\text { 작성방법: 이미 성취된 } \\
\text { 것처럼 과거 또는 현재 } \\
\text { 시제 동사로 시작 }\end{array}$ & $\begin{array}{l}\text { 각각의 목적달성도를 측 } \\
\text { 정하기 위한 질문이나 } \\
\text { 지표 등의 방법 } \\
\text { (수량, 질, 시간 포함) }\end{array}$ & $\begin{array}{l}\text { 필요정보 수집방법: 데 } \\
\text { 이터 수집 주체, 빈도, } \\
\text { 정보 수입원(source)기입 }\end{array}$ & $\begin{array}{l}\text { 목적에서 목표로 연계되 } \\
\text { 기 위해 충족되어야할 } \\
\text { 가정 }\end{array}$ \\
\hline $\begin{array}{l}\text { Output(산출물) } \\
\text { 목적달성의 위해 프로젝 } \\
\text { 트가 산출해야하는 결과 } \\
\text { 물, 서비스 또는 생산물 } \\
\text { 작성방법: 이미 성취된 } \\
\text { 것처럼 과거 또는 현재 } \\
\text { 시제 동사로 시작 }\end{array}$ & $\begin{array}{l}\text { 산출물 생산 정도를 측 } \\
\text { 정하기 위한 질문이나 } \\
\text { 지표 등의 방법. 일반적 } \\
\text { 으로 개발행위의 결과물 } \\
\text { 임. (수량, 질, 시간 포 } \\
\text { 함) }\end{array}$ & $\begin{array}{l}\text { 필요정보 수집방법: 데 } \\
\text { 이터 수집 주체, 빈도, } \\
\text { 정보 수입원(source)기입 }\end{array}$ & $\begin{array}{l}\text { 산출물에서 목적으로 연 } \\
\text { 계되기 위해 충족되어야 } \\
\text { 할 가정 }\end{array}$ \\
\hline $\begin{array}{l}\text { Activities } \\
\text { (사업구성요소/개발활동) } \\
\text { 산출물 생산을 위해 프 } \\
\text { 로젝트가 해야하는 활동 } \\
\text { 작성방법: 생산해야하는 } \\
\text { 것을 명사형으로 표현 }\end{array}$ & \multicolumn{2}{|c|}{$\begin{array}{l}\text { Input(투입/투입자원) } \\
\text { 개발행위의 결과는 산출물 수준에서 측정되므로 이 } \\
\text { 칸에는 투입요소를 기입 }\end{array}$} & $\begin{array}{l}\text { 개발행위에서 산출물로 } \\
\text { 연계되기 위해 충족되어 } \\
\text { 야할 가정 }\end{array}$ \\
\hline
\end{tabular}

* 출처: 박수영 (2009)

2) 논리모형모델(Logical Framework)의 역사, 개념, 작성법 등 보다 자세한 내용은 박수영 (2009) 참조 
그러나, 이 간단해 보이는 표 안에는 사업의 주요내용 뿐만 아니라, 개발협력사업 활동들이 달성 해야할 사업목적과 개발목표들이 일목요연한 논리관계를 가지고 정리되어 있으며, 각 단계별로 목적 과 목표달성을 측정할 지표와 지표별 입증수단까지 포함하고 있는 동시에, 사업추진과정에서의 모니 터링 및 평가를 위한 도구로도 사용된다. 이러한 높은 편리성으로 인해 Logframe은 개발협력사업의 성과관리를 위한 적절한 도구로서 널리 사용되고 있다.

Logframe은 수직 · 수평의 두 축을 중심으로 한 논리체계를 갖는다. 수직적 논리체계는 Logframe의 첫 번째 열인 Narrative Summary의 각 행 사이의 논리적 인과관계를 의미한다. 즉, 개발사업의 투입자원(Inputs)과 사업활동(Activities), 산출물(Outputs), 사업의 개발목적 (Purpose), 장기개발목표(Goal)를 설명하는 첫 번째 열인 Narrative Summary가 수직적으로 순차 적인 논리체계를 보인다는 것이다(〈그림1〉 참조). 이 수직적 논리체계가 바로 뒷 장에서 설명할 성 과분석모형이 가져야할 논리적인 인과관계(If-then Causality)이다.

\section{〈그림 1〉 Logframe의 수직적 논리관계}

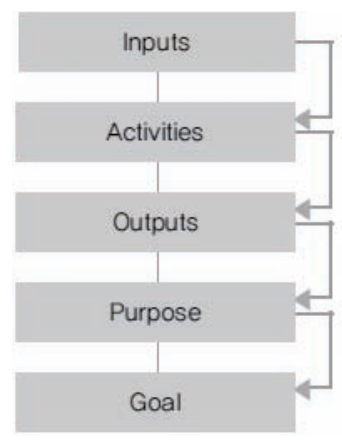

만약 자원이 모두 제공되면, 그렿다면 개발행위가 수행될 것이다

만약 개발행위가 모두 이행되면, 그렇다면 산출물이 생산될 것이다.

만약 산출물이 모두 생산되면, 그렇다면 목적이 달성될 것이다.

만약 목적이 달성되면, 상위목표달성에 기여할 것이다.

* 출처: 박수영 (2009)

하지만, 이러한 수직적 논리는 완벽한 것은 아니다. 왜냐하면 개발협력 사업에는 많은 위험요소 들이 존재하기 때문이다. 따라서 Logframe의 네 번째 열인 가정(Assumption)에서 계획 단계에 서 추정 가능한 위험요소들을 정리하여 배치한다. ${ }^{3)}$ 즉, Logframe의 수직적 논리체계는 Narrative Summary열과 같은 행에서의 Assumption열 간의 수평적 논리관계를 통해 완성된다. 즉 Narrative Summary의 각 행들을 모두 이행하고 동시에 동일한 행의 Assumption이 모두 충족되면 다음 단계 로의 이행이 가능하다는 것이다(〈그림 2〉참조).

3) Assumption은 각 목표가 한 단계 위의 목표로 이어지기 위해 해결되어야 하거나 회피되어야할 위험들을 말하며, 기관에 따라서는 Risks라는 용어로 사용되기도 한다(박수영, 2009). 


\section{〈그림 2〉 Logframe의 수직/수평적 논리관계}

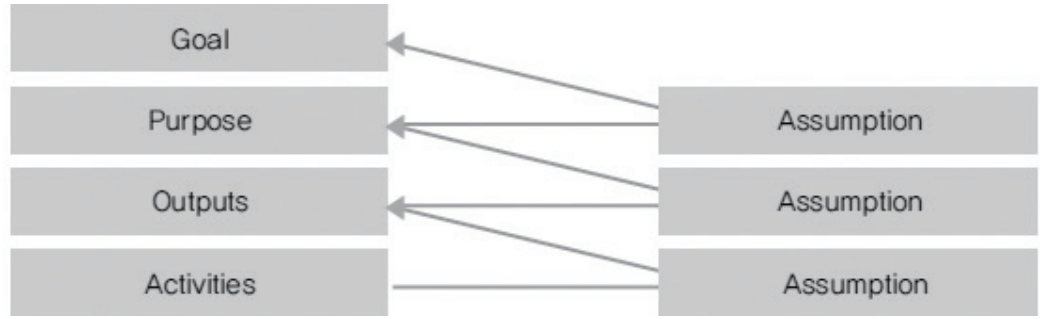

제I장

제II장

제III장

* 출처: 박수영 (2009)

Logframe은 이러한 수평적, 수직적 논리관계와 함께 Objectively Verifiable Indicator(OVI)열 과 Means of Verification(MoV)열을 통해 모니터링과 평가관리가 가능하도록 한다. 즉, Logframe 은 성과분석모형 도구 중 하나이며, 각 개발협력기관들은 Logframe을 기관 특성과 입장에 맞추어 약간씩 변형하여 사용하고 있는 것이다. 예를 들어 영국 DFID의 경우, 2009 년도에 아래와 같이 사 업관리를 위한 표준 Logframe형식을 Excel에 따라 연도별 모니터링이 가능하도록 하는 방식으로 개정하였다.

일반적으로 Logframe을 포함한 성과분석모형은 어떤 정책이나 사업이 기획된 내부적 논리성을 확인하고 이를 통해 목적과 목표들이 유기적이고 합리적으로 연계되어있는가를 점검하는데 유용하 게 활용된다. 특히 계획단계부터 대상 사업의 성공을 위한 핵심요소를 분석하고 가정들을 기술함으 로써 사업활동들이 논리적으로 도출되었는지 점검이 가능하도록 하는 장점이 있다. 또한, Logframe 은 계획단계에서부터 지표를 개발하여 모니터링과 평가를 고려하도록 하는 동시에 하나의 표 안에 사업의 목적과 산출물을 명확히 정리함으로써 이해관계자 모두가 사업의 핵심내용을 정확히 이해할 수 있도록 한다.

\section{Logframe의 한계}

이렇듯 현재 Logframe이 널리 쓰이고 있으나, 한계가 없는 것은 아니다. 이와 관련하여 여기서 는 Logframe이 갖는 한계를 총 7 가지로 정리하고자 한다. Logframe의 첫 번째 단점은 시간이 많 이 소요된다는 점이다. 개발사업을 처음 수행하는 실무자가 Logframe을 정확히 이해하고 작성하기 까지는 많은 교육과 훈련시간이 필요하다. 아울러 실제 참여적 방법론을 활용하여 Logframe을 정확 하게 작성하는 데에도 많은 시간이 요구된다. 
〈표 5〉DFID의 새로운 Logframe 양식
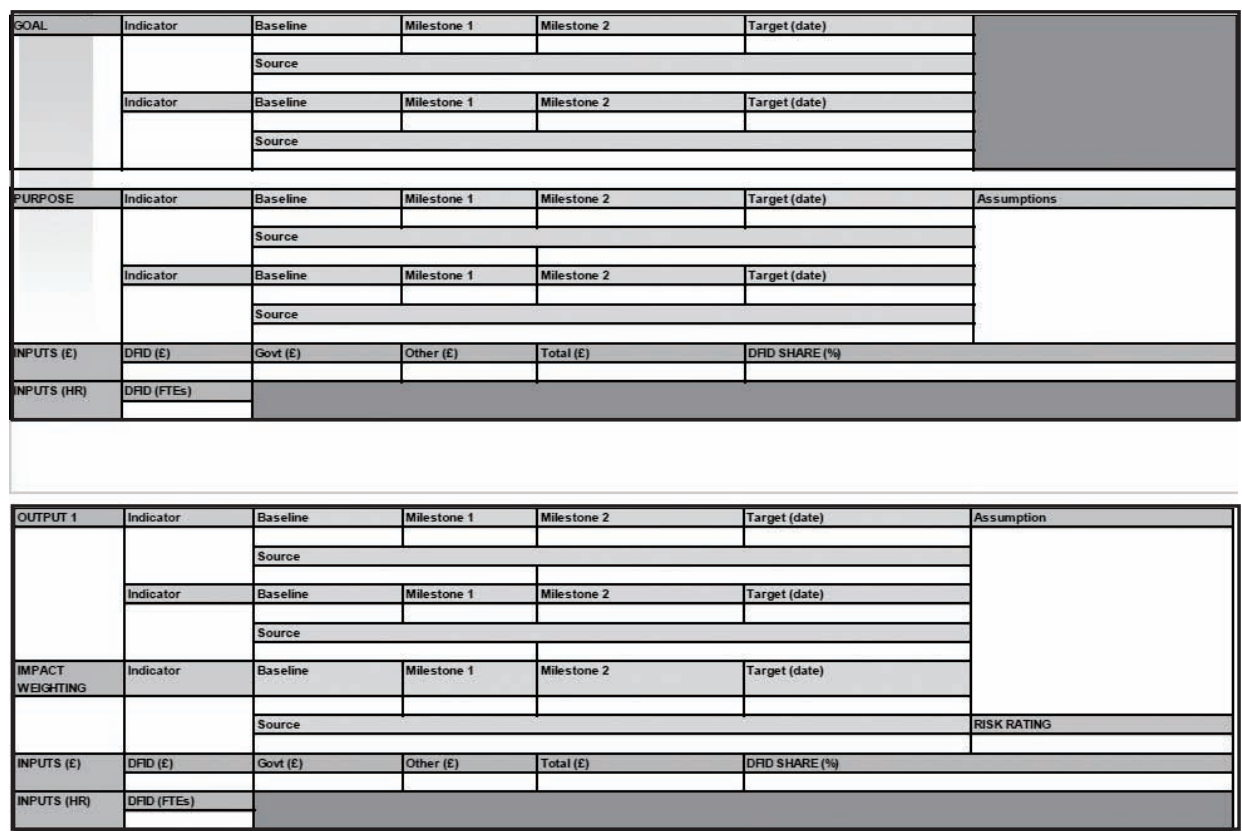

* 출처: DFID (2009)

두 번째로, 이보다 더 중요한 한계는 Logframe이 현실을 지나치게 단순화해서 해석한다는 점이 다. Logframe은 매우 복잡한 개발환경과 이해관계자들간의 다양한 관계를 매우 단순한 문구와 일 직선상의 논리관계로 표현한다. 이러한 지나친 단순화된 논리관계는 현실을 정확히 반영하지 못하여 유명무실해 질 가능성이 높다. 실제로 Logframe이 기획단계의 문서로만 작성되고 이후에는 수정, 보완되지 않는 경우도 종종 있다.

세 번째 한계는 Logframe의 인과관계 논리체계가 매우 서구적인 아이디어에 기반한다는 것이다. 이로 인해 실제 문화와 환경이 다른 개발도상국에서는 이러한 단순한 인과관계는 이해받지 못할 가 능성이 있다.

Logframe의 네 번째 한계는 작성방식 자체가 지나치게 문제에만 초점을 맞추어 진행됨에 따라 개발환경을 부정적으로 인식하도록 한다는 점이다. Logframe을 도출하기 위해 관계자들은 '문제분 석(Problem Analysis)'을 수행하여 핵심문제를 도출해야 한다. 이는 개발도상국이 갖고 있는 긍정 적인 역량과 능력을 파악하기보다는 부정적인 이미지를 강화시키는 기제로 사용될 수 있는 것이다. 실제 몇몇 기관에서는 긍정적 분석을 위해 이해관계자들이 갖고 있는 자원과 기술에 초점을 맞추 
는 역량분석(capacity Analysis)방식이나 긍정적 문제분석이라고 볼 수도 있는 목표분석(Objective Analysis)을 병행함으로써 이러한 한계를 보완하고 있다.

Logframe은 한편으로 실제 적용 시에도 한계를 보인다. Logframe에 너무 매몰되다보면 사업수 행 시 개발활동을 적절히 수행하기 보다는 지표를 측정하고 달성하는 데에만 집중하는 경우가 발생 할 수 있다. 이로 인해 프로젝트는 경직되고 변화하는 환경에 대한 적응성이 떨어지게 된다. 개발사 업환경은 변화무쌍함을 특징으로 한다. Logframe이 이러한 환경을 적기에 반영하여 수정, 보완되 지 못하는 상태에서 담당자가 계획단계에 설정된 지표 측정과 달성에만 치중한다면, 오히려 개발에 대한 기여도는 반감될 수 있는 것이다.

여섯 번째로, Logframe은 원래 투입, 산출물, 목적 등 각각의 행동들이 서로 다른 관리자들에 의 해 관리되는 대규모 프로젝트 수행에 적합하도록 만들어졌기 때문에 소규모 프로젝트에는 적합성이 떨어진다는 한계를 보인다.

마지막으로 Logframe은 정성분석보다는 정량분석에 치중해있기 때문에 관리자들이 정량화된 지 표 달성을 개발목표달성과 동일시하는 오류를 범할 소지가 있다는 점이다.

Logframe의 초창기 개발과 적용을 맡았던 사람들이 볼 때에는 현재의 Logframe은 본래 의도되 었던 사용방식과는 거리가 멀다. 오늘날 대부분의 개발협력기관들은 거의 변경이 불가능한 표준화된 템플릿을 가지고 Logframe을 완성하는 것을 사업수행에서 의무화하고 있으며, 이러한 도식화된 사 용이 Logframe의 한계를 더욱 두드러지게 했고, 이를 보완한 새로운 성과분석도구의 필요성이 더욱 대두되었다.

\section{IV. 변화분석(Theory of Change)과 성과관리}

앞 장에서 서술한 성과분석모형과 Logframe의 한계를 극복하는 하나의 방편으로서 최근 변화분 석(Theory of Change, 이하 ToC)라는 개념이 주목을 받고 있다. ToC의 사용은 국제개발에서 점 차 늘고 있는 추세이며, 공여국, 양자 및 다자 개발기관, 시민사회단체, 국제 $\mathrm{NGO}$, 개발성과 지원 (support)을 위한 연구프로그램 등 폭넓은 범위에서 활용되고 있다. 그러나 아직까지 합의된 ToC의 정의와 형태가 존재하지 않는 것도 사실이다. 이 장에서는 $\mathrm{ToC}$ 의 다양한 정의와 활용법을 살펴본다.

\section{ToC의 다양한 정의}

$\mathrm{ToC}$ 에 대한 가장 유명한 정의 중 하나는 ' $\mathrm{ToC}$ 란 어떻게 그리고 왜 특정 사업이 작동하는지에 대 
한 이론(Weiss, 1995)' 이다. Anderson (2004)은 Weiss의 정의 보다 구체화하여, 특정 프로그램 이나 개입의 성과와 활동들 간의 관계와 장기목표로 이르는 단계들을 모두 설명하는 가정들에 대 한 분석으로 $\mathrm{ToC}$ 를 정의했다. 이 외에도 ToC는 '지도(Roadmap), 청사진, 변화의 동력(engine of change), 활동분석(theory of action)등의 다양한 용어로 불린다' (Reisman, Jane, Anne Gienapp, and Sara Stachowiak, 2007).

$\mathrm{ToC}$ 에 대해 합치된 정의는 없지만, 일련의 설명들이 보여주듯이 ToC는 활동과 성과관의 관계를 분석하는 방식으로 정의된다고 할 수 있다. 실제 $\mathrm{ToC}$ 를 성과관리에 적용하는 사업수행기관들 역시 $\mathrm{ToC}$ 를 이러한 활동과 성과관의 인과관계로 정의하는 것으로 보인다. 예를 들어, 세계은행은 $\mathrm{ToC}$ 를 장기변화를 일으키는데 필요한 일련의 중 - 단기 목적간의 논리적 인과관계로 정의하고, 성과분석모 형의 핵심 논리로 활용한다(World Bank, 2012). DFID는 ToC를 주어진 상황(context)에서 변화를 일으키고자 하는 이니셔티브나 프로그램의 계획 및 실행, 평가 과정에 비판적인 사고를 적용하는 방 식으로 이해한다. 즉, ToC는 활동(activities)에서부터 영향을 미치고자 하는 변화에 이르기까지 일 련의 이니셔티브들의 논리적 연속상태를 정리하는 하나의 도구이자 방법론으로 이해되는 것이다. 영 향력 있는 평가 전문가인 릭 데이비스(Rick Davies)는 희망했던 특정 성과를 유발할 것으로 기대되 는 일련의 사건들의 연속(sequence of events)에 대한 서술로 ToC를 정의하였다(DFID, 2012).

$\mathrm{ToC}$ 를 실제 지역사회사업 평가에 활용한 ActKnowledge 역시 ToC를 논리적 인과관계로 정의 함으로써 논리관계를 정리하여 지도나 표로 도식화한다. 따라서, $\mathrm{ToC}$ 는 궁극적으로 프로그램 논리 (programe logic)나 계획(initiative)을 의미한다고 할 수 있다(ActKnowledge, 2003). ToC는 장 기목표를 정의하고 역으로 장기목표 구현을 위해 필요한 변화들을 단계적으로 도식화되며, 확인된 변화들은 각 목적들 간의 논리적 상관관계를 보여주는 인과관계에 따라 도표나 그림으로 보여진다. 즉, ToC는 실제 활용될 때 '논리모형(Logic Model)'의 변종으로 사용되며, '만약 정치경제이슈에 대 한 주요 이해관계자간의 건설적인 활동들이 있다면, 그렇다면 이는 정보의 흐름을 향상시켜 정책이 나 의사결정의 변화로 이어질 것이다 (CARE International UK, 2012: p.5)'와 같은 만약...그렇다 면(If...Then)의 관계로 이해된다.

한편, ToC의 확산을 이끌었던 영향력 있는 실무 가이드라인인 The Community builders' Approach to Theory of Change ${ }^{4)}$ 를 저술했던 Anderson(2011)은 ToC를 복잡한 사회문제 해결을 위해 발전된 산출물로 정의했다. Anderson(2005)은 기본적인 ToC는 장기성과를 산출하기위해 초

4) 이 가이드라인은 1990년도에 Aspen Institute가 평가자와 커뮤니티 개발 프로그래머들을 동원한 상태에서 프로그 램이론을 적용하여 복잡한 커뮤니티 이니셔티브를 평가하고자 한 시도의 일환으로서 2005년 Anderson에 의해 개발되었다(Connell and Kubisch, 1998). 
기 및 중기 성과물들이 단계적으로 어떻게 분류되어야하는지를 설명하며, 보다 완성도 높은 ToC는 변화가 발생할 과정들에 대한 가정들을 보여주고, 바람직한 장기변화를 위해 필요한 단기 및 중기 목적들을 달성할 방법을 구체화하여 문서화한다고 주장하였다. Anderson(2011)은 이를 종합하여 $\mathrm{ToC}$ 를 지역주민에 의해 도출된 장기목표달성에 필요한 단기 및 중기 변화를 묘사하는 포괄적인 그 림을 도출하는 비판적, 분석적 활동들의 산물로 정의하였다.

다른 한편에서는 ToC를 일종의 보다 심층적인 사색과정(reflective process)으로 보았다. 즉 변

제I장

제II장

제III장

화에 대한 철학과 가치, 세계관 등은 이니셔티브의 성과(outcome)로서의 변화가 어떻게, 그리고 왜 일어나는지에 대한 기본 가설들을 보다 명료하게 만들어주는데, ToC를 이러한 변화의 철학 및 가치, 세계관 등에 대한 지도(mapping)이자 대화에 기반한 분석(dialogue-based analysis)으로 보는 것 이다. Comic Relief 리뷰는 ToC의 변화양상에 대한 모색은 학습에 기반해 이루어지는 동시에, 변화 의 발생과정, 이것이 특정한 상황(context)이나 섹터, 집단 내에서 갖는 함의 등에 대해 계속 진행되 는(ongoing) 일련의 사색(reflective)의 과정이라고 정의하였다.

1990년대 미국에서 처음으로 지역사업 평가방법론과 실제 평가수행 방식을 개선하고자 하는 시 도의 일환으로서 나타난 ToC는(Stein and Valters, 2012) 이후 사업투자자들의 사용 요구가 증대 함에 따라 점차 개발사업에서 주류화되었다. 그러나, 개발협력에서 $\mathrm{ToC}$ 에 대해 공식적으로 합의된 정의는 아직 도출되지 않았으며, 일부는 아직 $\mathrm{ToC}$ 를 유행어로 정도로 취급하기도 한다. 이러한 상 황에도 불구하고 $\mathrm{ToC}$ 는 보다 넓고 복잡한 개발협력 상황을 분석하고자하는 개발협력 관련 기관들의 요구를 반영하며 현재까지 계속적으로 변화, 발전하고 있다.

결론적으로, 현재 ToC는 서술(statement)나 문서와 같은 산출물(Product) 또는 하나의 방법론으 로서 일련의 분석 과정이나 도구(Process or Tool)로 정의되는 것으로 보인다. 즉, ToC는 복잡한 개 발협력의 맥락(Context)속에서 특정사업의 장기성과를 도출하는 활동들의 인과관계를 분석하는 방 식 또는 이렇게 분석된 관계를 정리하여 글, 다이어그램, 그림, 표 등으로 나타낸 산출물 모두를 의 미한다고 할 수 있다. 최소한으로, ToC는 아래 박스의 다섯 가지 요소들에 대한 논의를 모두 포함해 야 한다.

\section{2. $\mathrm{ToC}$ 의 사용법}

$\mathrm{ToC}$ 적인 사고는 다양한 방식으로 사용될 수 있다. 상위 정책 수준에서 정책이 이끌어낼 변화 과 정 탐색, 사업 활동의 내부적 논리 설명, 중요한 변화를 초래할 인과관계의 연결고리에 대한 가설 성 립에 이르기까지 $\mathrm{ToC}$ 의 사용 범위는 넓다. 이 절에서는 개발정책수립, 개발기관의 전략 수립 또는 사업기획과 평가에서 $\mathrm{ToC}$ 의 활용방식을 고찰해 본다. 


\section{〈BOX 1〉 ToC의 핵심요소}

주어진 상황(Context). $\triangle$ 사회, 정치, 환경적 조건을 포함한 이니셔티브 상황, $\triangle$ 프로젝트가 영향을 미치 고자 하는 문제들의 현 상태, $\triangle$ 변화에 영향을 미칠 수 있는 다른 행위자들의 주어진 상황

장기 변화(long-term change). 이니셔티브가 지원하고자 하는 장기적 변화 및 이를 통한 궁극적인 이익

변화 프로세스/연속(process/sequence of change). 희망하는 장기 성과를 이끌어낼 것으로 예상되는 변화 프로세스 및 변화의 연속

가정(Assumptions). 이러한 변화들이 어떻게 발생하는가에 대한 가정(assumptions). 활동(activities)와 산 출물(outputs)이 원하던 방향대로 변화에 영향을 미치기에 적절한지의 여부에 대한 확인 작업.

도표 및 내러티브 요약(Diagram and narrative summary). 논의의 성과를 담아 내는 작업.

* 출처: Isabel Vogel(2012)

\section{1) 국별, 섹터별 정책 분석}

$\mathrm{ToC}$ 의 첫 번째 활용법은 국별 또는 섹터별 전략 수립을 위한 상황분석이다. 상위 단계(high level) 정책 및 전략의 타당성을 점검하기 위해 수원국의 변화와 관련된 핵심적인 상황(context) 및 변화의 조건들을 분석하고, 변화를 위한 여러 가설들을 수립한 뒤, 가설에 따라 변화경로를 세우고 그 경로의 타당성의 입증지표를 확인한다. 이렇게 도출된 ToC 결과를 Logframe 등의 성과분석모형 으로 변환하여 정책을 집행, 모니터링 및 평가한다. 이러한 상위 수준의 ToC 결과를 도식화함으로써 구체적인 국별 상황에 대한 총체적인(generic) 분석이 가능해진다.

$\mathrm{ToC}$ 는 변화에 대한 넓은 개념적 프레임워크를 제공하며, 이러한 개념적 프레임워크는 특정한 상 황에 대한 전략적 선택을 하는데 사용되어진다. 또한 이러한 개념적 프레임워크는 구체적인 이행 상 황에서 발생하는 변화에 영향을 미치기 위한 개입(intervention) 옵션들을 파악하는 기반으로서 활 용되거나 평가 질문에 포커스를 맞추는데 사용된다. 이러한 정책 및 전략 수준의 ToC는 공여기관들 의 정책부서 등과 관련되는 경향이 있다.

\section{2) 사업계획 수립}

$\mathrm{ToC}$ 는 사업계획 수립에도 활용된다. 사업이 달성하고자 하는 장기목표를 세우고 역으로 이 목표 달성에 필요한 중간 및 초기 단계의 목적들을 분석하고 이러한 다른 목적간의 인과관계를 명확히 하 여, 적절한 사업계획을 수립하는 것을 가능하게 한다. 계획수립과 관련하여 $\mathrm{ToC}$ 는 주로 6 단계를 거 쳐 수행된다(〈Box 2〉 참조). 사업계획수립을 위한 ToC 과정을 Logframe수립을 위한 분석 과정과 
비교해보면 그 차이가 보다 쉽게 이해된다. Logframe이 사업이 대응해야할 개발관련 문제의 인과관 계를 분석하여 핵심문제(core problem)을 최종적으로 도출하고 이를 긍정문으로 바꿔 사업이 달성 해야할 개발 목표로 변환한다면, ToC는 이와는 정반대로 일단 달성해야할 목표를 먼저 세워놓고 목 표 수립을 위해 필요한 행동들을 역으로 추적한다. 또한, Logframe의 분석이 각 단계별로 중복되는 연관성을 인정하지 않는데 반해, ToC는 각 행위들간의 복잡한 관계를 용인한다 (〈그림 3 〉참조). 이 렇게하여 보다 복잡한 성과관계도가 완성되면 이에 대해 가정을 도출하고 지표를 개발하는 것은 두 방식이 유사하다.

\section{3) 평가}

평가자들은 평가대상별로 기존에 수행된 $\mathrm{ToC}$ 과정을 확인하여 선택된 개입의 적절성을 판단해 야하며, 이를 위해 다양한 정보를 필요로 한다. 심도 있는 평가를 위해서 평가자들은 의도된 수혜자 그룹에 대한 사업 효과성과 사업을 둘러싼 환경의 폭넓은 변화에 관련된 다양한 이슈를 명확히 이해

\section{〈BOX 2〉사업계획수립을 위한 6단계 프로세스}

\section{1. 장기목표 도출}

2. 역분석을 통해 단기 및 중기 성과들 도출 및 매핑

3. 성과관계도 완성

4. 가정 도출

5. 지표 개발

6. 사업계획 수립

* 출처: Isabel Vogel(2012)

해야 한다. 평가대상으로 선택된 전략이나 사업의 적절성과 효과성을 평가하기 위해서는 이러한 개 입과 다른 선택이 있었는지, 다른 개입은 선택된 개입과 비교하여 어떠한지 등을 확인할 필요가 있 다. 평가를 위한 ToC는 $\triangle$ 원인-결과, $\triangle$ 상이한 변화경로, $\triangle$ 행위자, $\triangle$ 프로그램 작동 메커니즘, $\triangle$ 영향력을 가지고 있는 중요한 상황적 조건 등에 대해 상세한 분석을 가능토록 한다. ToC는 정책이나 사업의 기획 단계와 집행간의 차이점을 검토할 수 있게 하여, 보다 정확한 평가를 가능케 한다. 


\section{ToC와 Logframe}

1960년대부터 개발협력사업 평가를 위한 여러 접근법들이 논의되었다. 현재 Logframe이나 ToC 는 프로그램 이론(Program Theory) 접근방식에 기초한다. 프로그램 이론은 평가를 위해 $\triangle$ 프로그 램의 이론적인 근거가 무엇인지, $\triangle$ 프로그램 설계자가 투입물(inputs)과 성과물(outcomes)사이의 연결고리를 어떻게 보는지, $\triangle$ 프로그램이 어떻게 작동하도록 의도되었는지 등에 대해 보다 집중할 것을 촉구한다(Funnell and Rogers, 2011). 따라서 동일한 접근법에서 출발한 ToC와 Logframe 간에는 명확한 구분이 어려운 부분도 존재한다.

하지만 두 방식 간에는 분명한 차이 역시 존재한다. 단순하게 말하면 ToC와 Logframe의 차이는 위의 그림으로 표현될 수 있다〈그림 3〉. ToC는 각 성과별 하나 이상의 복잡한 인과관계 분석을 가능 하게 한다. 반면에 Logframe은 개입-산출물-목적-장기목표 간의 단일한 인과관계만을 인정한다. 이는 Logframe이 개입-산출물-목적-장기목표 간의 단일한 인과관계만을 표현하는 것과는 차이를 보인다. ToC는 또한 Logframe과는 달리 여러 다른 형태로 표현될 수 있으며 이는 4행과 4열의 정 형화된 틀만을 가진 Logframe과는 매우 다르다. 따라서 ToC는 4단계 이상 또는 이하의 다양한 변 화과정을 표현할 수 있다. 일반적으로 Logframe은 모니터링에 ToC는 평가에 더 유용하다.

또 다른 차이점은 ToC는 Logframe이 보여주지 못하는 중간고리(missing middle)를 확인할 수 있게 한다는 점이다. 개별사업의 즉각적인 결과가 어떻게 다른 수준의 변화들에 영향을 미치고 이것이 장기적으로 성과(outcomes) 및 영향(impact)으로 어떻게 이어지는가에 대한 인과관계를

\section{〈그림 3〉 ToC와 Logframe}

[ToC]

가능한 모든 변화경로를 통해 큰 그림을 제시- 복잡한 인과관계

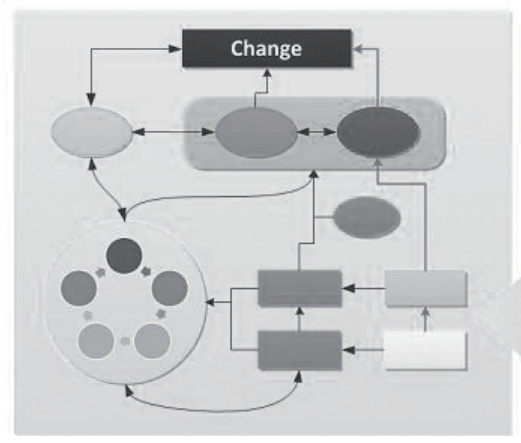

\section{[Logframe]}

프로그램이 의도한 변화경로만을 제시- 단일한 인과관계

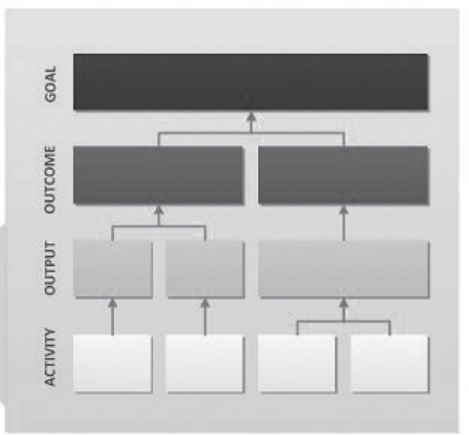

* 출처: http://www.tools4dev.org 
Logframe은 보여주지 못한다. 그러나 logframe이 숨기고 있는 이 ‘잃어버린 중간고리’는 ToC적 사 고를 통해 연결될 수 있다. ToC를 통해 프로그램 결과물과 기여하고자 하는 개발 성과 간에 발생하 는 사건연속(sequence of events)의 근간이 되는 연결고리와 반복 프로세스에 관한 사람들의 생각 과 이론을 분석하고 매핑함으로써 이 ‘잃어버린 중간고리’를 보다 명확하게 만들 수 있다.

즉, ToC는 위 그림의 '화살표들의 이면에서(behind the arrows)' 어떠한 일이 진행되고 있는지를 제II장 명확하게 알아내고, 논리상의 취약점이 무엇인지를 밝혀내며, 주어진 상황에서 얼마나 실질적으로 이러한 취약점들을 해결할 수 있을지를 알아내는 등의 작업을 가능하게 한다. 이를 통해 ToC는 정책 이나 사업 추진 및 평가와 모니터링을 보다 견고하게 추진할 수 있게 한다.

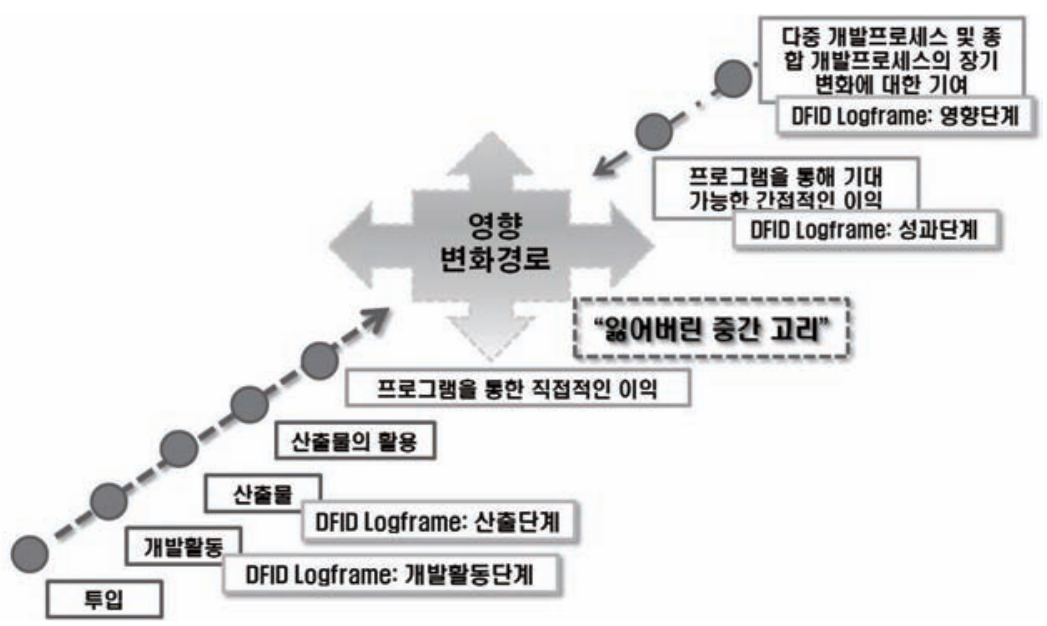

* 출처: 저자가 재작성. Isabel Vogel (2012), GIZ (2009), Douthwaite et al (2003)

\section{V. 결론}

본 연구에서는 개발협력사업 성과관리방법의 핵심이 되는 '성과분석모형'과 그에 기반한 Logframe, 그리고 분석도구이자 접근법으로 활용되는 $\mathrm{ToC}$ 의 정의와 활용법에 대해 살펴보았다. Logframe은 널리 활용되는 유용한 성과관리도구이기는 하나 유일한 도구는 아니며 장점과 함께 많 은 한계점도 갖고 있다. 사업계획이나 모니터링을 위해서 Logframe이 유용하게 쓰일 수는 있으나, 
다른 공여기관들의 사례나 Logframe 자체의 특성을 고려 시, 심층 분석이나 평가, 정책개발, 개발 환경 분석 등을 위해서는 인과관계간의 복잡성과 다양한 경로 확인이 가능한 $\mathrm{ToC}$ 를 활용하는 것이 더 효과적일 수 있다. ToC는 변화에 대한 보다 비판적인 분석이 가능하고, 여러 인과관계경로 분석 을 통해 서로 다른 옵션들을 확인할 수 있다는 장점이 있다.

따라서, $\mathrm{KOICA}$ 는 국별정책이나 분야별 전략 수립시 $\mathrm{ToC}$ 를 활용하여 현황분석을 수행하고, 성 과분석모형을 활용하여 정책과 전략의 성과관리를 강화하는 방안을 모색할 수 있겠다. 아울러, 평가 수행시에도 $\mathrm{ToC}$ 를 활용하여 평가분석의 질을 제고하는 방안을 도입함으로써 전사적인 성과관리체 계 강화에 활용하도록 해야 할 것이다. 


\section{〈참고문헌〉}

\section{1. 국내문헌}

제I장

박수영, 2009.『프로젝트관리와 평가: 프로젝트 기획·모니터링 및 평가방법론』. 성남:한국 국제협력단

\section{2. 국외문헌}

Anderson, A. 2004. "Theory of Change as a Tool for Strategic Planning: A Report on Early Experiences." The Aspen Institute: Roundtable on Community Change. Retrieved from http://www. theoryofchange.org/pdf/tocII_final4. pdf

Batchelor, S. Fisher, C. and Beynon, P. 2013. "Learning about Theories of Change and Embedding Reflection." IDS Practice Paper in Brief 15. Brighton: Institute of Development Studies(IDS). Retrieved from http://opendocs. ids.ac.uk/opendocs/bitstream/123456789/2996/1/PP\%20InBrief\%2015\%20 FINAL.pdf

Stein, D and Valters, C. 2012. "Understanding Theory of Change in International Development: A Review of Existing Knowledge.” JSRP Paper 1. The Justice and Security Research Programme(JSRP), the Asia Foundation. Retrieved from http://www. theoryofchange.org/wp-content/uploads/toco_library/ pdf/UNDERSTANDINGTHEORYOFChangeSteinValtersPN.pdf

Sue C. Funnell, Patricia J. Rogers. 2011. Purposeful Program Theory: Effective Use of Theories of Change and Logic Models. San Francisco: Jossey-Bass/Wiley

Tapline, D. Cark, H. Clark, E. and Colby, D. 2013. "A Series of Papers to Support Development of Theories of Change Based on Practice in the Field." Theory of Change Technical Papers. Actknowledge. Retrieved from http:// www.theoryofchange.org/wp-content/uploads/toco_library/pdf/ToC-TechPapers.pdf

Valters, C. 2014. "Theories of Change in International Development: Communication, Learing, or Accountability?" Retrieved from http://www.lse.ac.uk/ internationalDevelopment/research/JSRP/downloads/JSRP17.Valters. pdf 
Vogel, Isabel. 2011. "Review Report: Review of the use of "Theory of Change' in international development." Retrieved from http://www. tools $4 \mathrm{dev}$. org/resources/theory-of-change-vs-logical-framework-whats-thedifference-in-practice/

Weiss, C.H. 1995. Nothing as Practical as Good Theory: Exploring Theory-Based Evaluation for Comprehensive Community Initiatives for Children and Families. Washington D.C.: The Aspen Institute

World Bank. 2012. "Designing a Results Framework for Achieving Results: A How-to Guide." Washington D.C.: World Bank. Retrieved from http://siteresources. worldbank.org/EXTEVACAPDEV/Resources/designing_results_framework. pdf 